\title{
Linfoma Difuso de grandes células B rico em células T/Histiócitos com características do Linfoma de Hodgkin de Predomínio Nodular Linfocitário: Relato de caso
}

\section{T Cell/Histiocyte Rich Large B Cell Lymphoma with features of Nodular Lymphocyte-Predominant Hodgkin Lymphoma: Case Report}

\author{
Giovanna Alves Peruzini*†, Beatriz Barboza Reis Queiroz ${ }^{\dagger}$, Iago Caetano Cariello ${ }^{\dagger}$, Tiago de Oliveira Boechat ${ }^{\ddagger}$
}

Como citar esse artigo. Peruzini, G.A;

Queiroz, B.B.R; Cariello, I.C; Boechat, T.O. Linfoma Difuso de grandes células B rico em células T/Histiócitos com características do Linfoma de Hodgkin de Predomínio Nodular Linfocitário: Relato de caso. Revista de Saúde. 2020 Jan./Jun.; 11 (1): 05-09.

\section{Resumo}

A atual classificação dos linfomas é baseada em um complexo sistema de características clínicas, morfológicas, imunofenotípicas e moleculares. O presente relato tem como objetivo descrever um caso de diagnóstico desafiador de um linfoma com características do Linfoma de Hodgkin de Predomínio Nodular Linfocitário (LHPNL) e Linfoma B Rico em células T/Histiócitos (LBRCT/H). Paciente, 38 anos, sem comorbidades compareceu ao ambulatório com queixa de linfonodomegalias generalizadas há aproximadamente 4 anos, com aumento progressivo ao longo dos anos, associado a emagrecimento de $20 \mathrm{~kg}$, sudorese noturna, febre e tosse. Ao exame físico, presença de massa bulky em região inguinal direita de $28 \mathrm{~cm}$ e edema ipsilateral. $\mathrm{O}$ histopatológico e o estudo imuno-histoquímico não puderam diferenciar entre LHPNL em LBRCT/H. O caso foi conduzido como LBRCT/H devido apresentação clínica avançada, com massa bulky e sintomas B, refletindo o caráter agressivo da doença. O linfoma de Hodgkin (LH) é uma neoplasia maligna rara de células B e, no que diz respeito a transformação para o Linfoma Difuso de grandes células B (LDGCB), um levantamento mostrou que 3-6\% dos LHPNL irão se transformar em um LDGCB de caráter agressivo ou podem, ainda, apresentar simultaneamente um LHPNL e um LDGCB4. Isto pode alterar o curso e a escolha do tratamento, já que existem protocolos distintos dependendo do tipo histológico da doença. Deve-se, também, levar em consideração as manifestações clínicas da doença, pois, como no estudo em questão, pode haver dúvida diagnóstica através de exames complementares.

Palavras-chave: Linfoma Difuso de Grandes Células B, Doença de Hodgkin, Linfoma não Hodgkin.

\begin{abstract}
The current classification of lymphomas is based on a complex system of clinical, morphological, immunophenotypic and molecular features. This case report aims to describe a challenging diagnostic case of a lymphoma with features of the Nodular Lymphocyte-Predominant Hodgkin Lymphoma (NLPHL) and T Cell/Histiocyte Rich Large B Cell Lymphoma (THRLBCL). Patient with 38 years old, without comorbidities, attended the outpatient clinic complaining of generalized lymphnodes enlargement for about four years, with progressive increase over the years, associated with weight loss (20kg), night sweats, fever and cough. On physical examination, presence of bulky tumor in the right inguinal region $(28 \mathrm{~cm})$ and ipsilateral edema. The histopathological examination and the immunohistochemical study could not differentiate between NLPHL and THRLBCL. The case was conducted as THRLBCL due to its advanced clinical presentation, with the bulky tumor and the B symptoms, reflecting the aggressive character of the disease. Hodgkin Lymphoma (HL) is a rare malignant B-cell neoplasm and, with regard to the transformation to the Diffuse Large B Cell Lymphoma (DLBCL), a survey showed that 3-6\% of NLPHL will turn into an aggressive DLBCL or they may present simultaneously a NLPHL and a DLBCL. This may change the course and choice of the treatment as there are different protocols depending on the histological type of the disease. Account should also be taken of the clinical manifestations of the disease, because, as in this study, there may be diagnostic doubt through the complementary exams.
\end{abstract}

Keywords: Diffuse Large B Cell Lymphoma; Hodgkin Lymphoma; Not Hodgkin Lymphoma.

\section{Introdução}

Os linfomas constituem um grupo de doenças neoplásicas malignas originários de células linfoides e são morfologicamente divididos em Linfomas não Hodgkin e Linfomas de Hodgkin ${ }^{1}$.

A atual classificação dos linfomas é baseada em um complexo sistema de características clínicas, morfológicas, imunofenotípicas e moleculares, de forma a classificá-los precisamente. No entanto, alguns casos são difíceis de serem enquadrados em uma única categoria específica, uma vez que demonstram características sobrepostas entre grupos de linfomas de variado prognóstico e abordagem terapêutica.

Nesses casos, fazer um diagnóstico correto é um desafio de grande importância, uma vez que irá nortear todo o tratamento e evolução do caso. Comumente essas dificuldades diagnósticas ocorrem entre o Linfoma de Hodgkin de Predomínio Nodular Linfocitário (LHPNL), 
Linfoma Difuso de Grandes Células B (LDGCB) e o Linfoma de Burkitt. O presente relato tem como objetivo descrever um caso de diagnóstico desafiador de um linfoma com características do LHPNL e Linfoma B Rico em células T/Histiócitos (LBRCT/H), visando distinguir os dois subtipos por meio das características clínicas, morfológicas e evolução de acordo com o tratamento instaurado.

\section{Relato de Caso}

Paciente, 38 anos, sem comorbidades, tabagista e etilista social, compareceu ao Ambulatório de Hematologia do Hospital Universitário de Vassouras com queixa de linfonodomegalias generalizadas há aproximadamente 4 anos, com aumento progressivo ao longo dos anos, associado a emagrecimento de $20 \mathrm{~kg}$, sudorese noturna, febre ocasional, tosse seca, massa inguinal direita e edema de membro inferior direito.

Ao exame físico, ausência de hepatoesplenomegalia, presença de massa bulky em região inguinal direita (Figura 1) de $28 \mathrm{~cm}$ em seu maior diâmetro com ulcerações e presença de secreção e edema ipsilateral (Figura 2). Presença de linfonodos axilares bilaterais de $3 \mathrm{~cm}$ e microadenopatia cervical.

Nos exames complementares observaram-se medula óssea normocelular, sem infiltração tumoral, raio-x de tórax evidenciando consolidações peri-hilares e em ápice esquerdo, Tomografia Computadorizada (TC) de tórax com linfonodomegalias mediastinais e hilares e consolidações pulmonares em lobos superiores com pequenas escavações, TC de abdome evidenciando múltiplos nódulos hepáticos, linfonodomegalias e conglomerados intracavitários e em retroperitônio e bulky na região inguinal direita e TC de pescoço evidenciou formação ovalada cervical esquerda de 4,2 x $3,7 \mathrm{~cm}$ inferior a tireoide. Doppler de membro inferior direito não indicava presença de trombose venosa profunda.

A biópsia linfonodal inguinal direita evidenciou linfonodo com arquitetura alterada as custas de proliferação monomórfica difusa de linfócitos pequenos entremeados por focos de necrose, presença de figuras de mitoses, compatível com doença linfoproliferativa. A Imuno-Histoquímica revelou linfonodo com proliferação de células grandes e atípicas em meio a numerosos pequenos linfócitos T e histiócitos, linfócitos $\mathrm{T}$ por vezes circundando células grandes atípicas com imunoexpressão de marcadores B (Figura 3). As células neoplásicas foram positivas para CD20, PAX-5, CD79a e OCT-2, CD-45, BCL-6, BCL-2 e MUM-1.

O histopatológico e o estudo imuno-histoquímico não puderam diferenciar entre LHPNL em LBRCT/H. $\mathrm{O}$ caso foi conduzido como LBRCT/H devido apresentação clínica avançada, com massa bulky e sintomas $\mathrm{B}$, refletindo o caráter agressivo da doença. O estadiamento Ann Arbor foi definido como Estágio IVBX, sendo iniciado tratamento com 6 ciclos de R-CHOP (Rituximab, Ciclofosfamida, Doxorrubicina, Vincristina e Prednisona), protocolo de primeira linha para LBRCT/H, apresentando redução $>50 \%$ do tamanho da massa inguinal (Figuras 4Ae 4B) e resolução completa das outras adenomegalias periféricas. No presente momento aguarda realização do PET-TC para melhor definição de resposta e encaminhamento para radioterapia de sítio envolvido como consolidação.

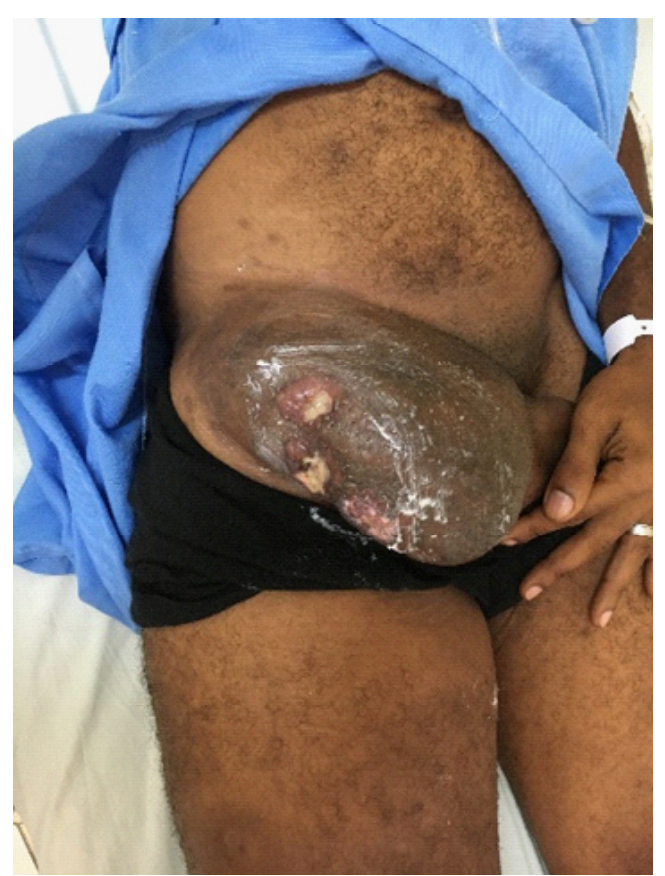

Figura 1 - Massa bulky em região inguinal direita 


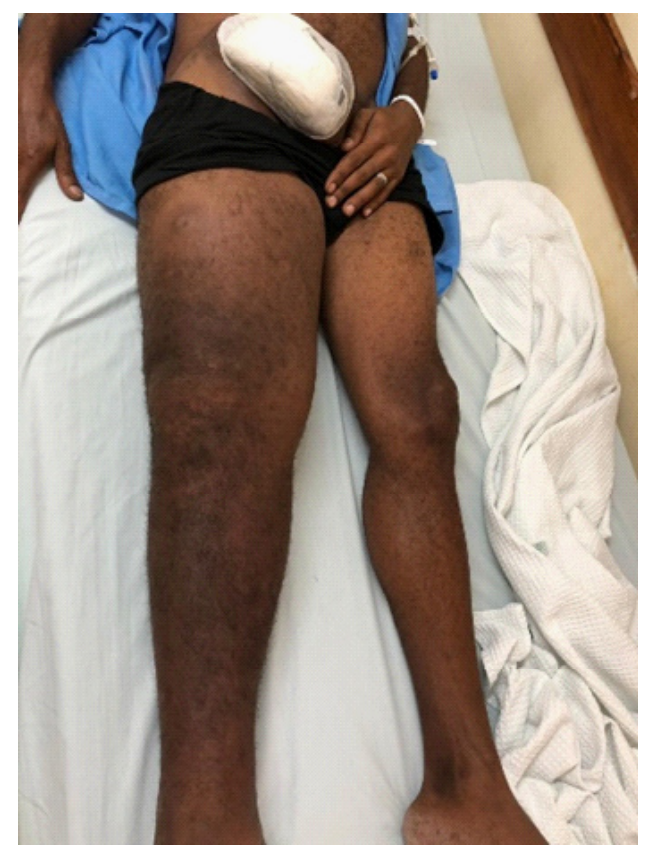

Figura 2 - Massa bulky à direita e edema em membro inferior ipsilateral

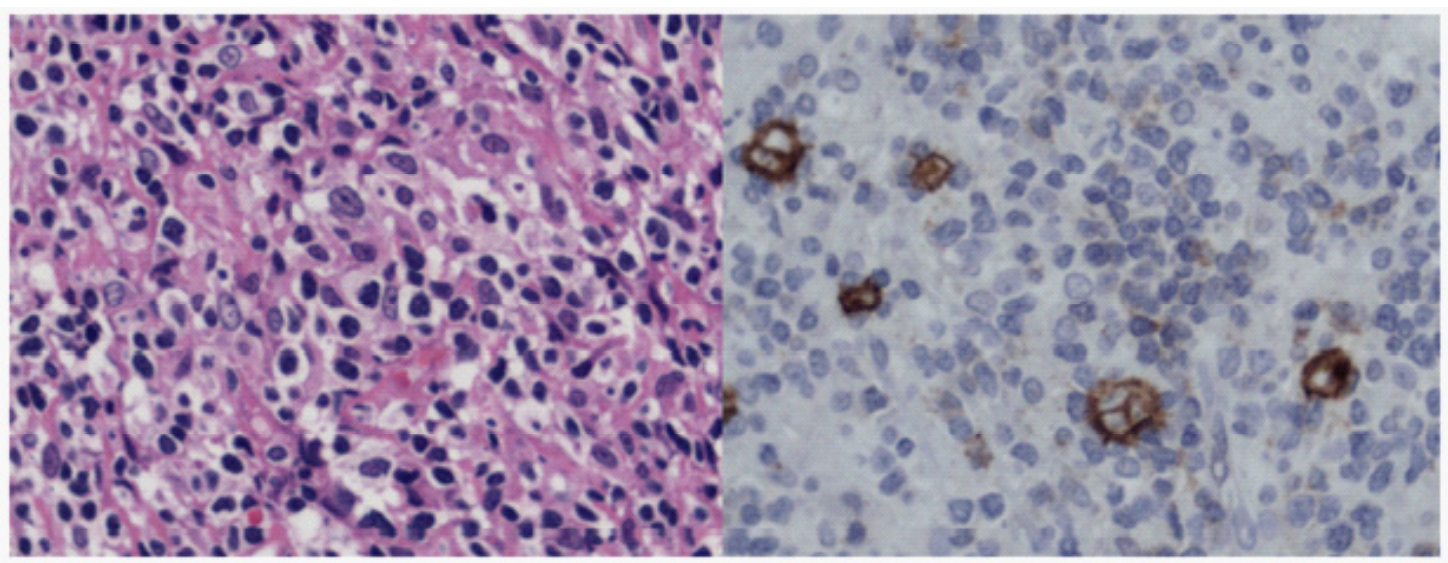

Figura 3 - Imuno-Histoquímica evidenciando conjunto de achados compatíveis com linfoma de grandes células B rico em células T. Há formação de nódulos sem células dendríticas foliculares, embora o padrão nodular da neoplasia e a presença de linfócitos $\mathrm{T}$ circundando células grandes atípicas favoreça a suspeição de linfoma de Hodgkin com predominância linfocítica nodular.
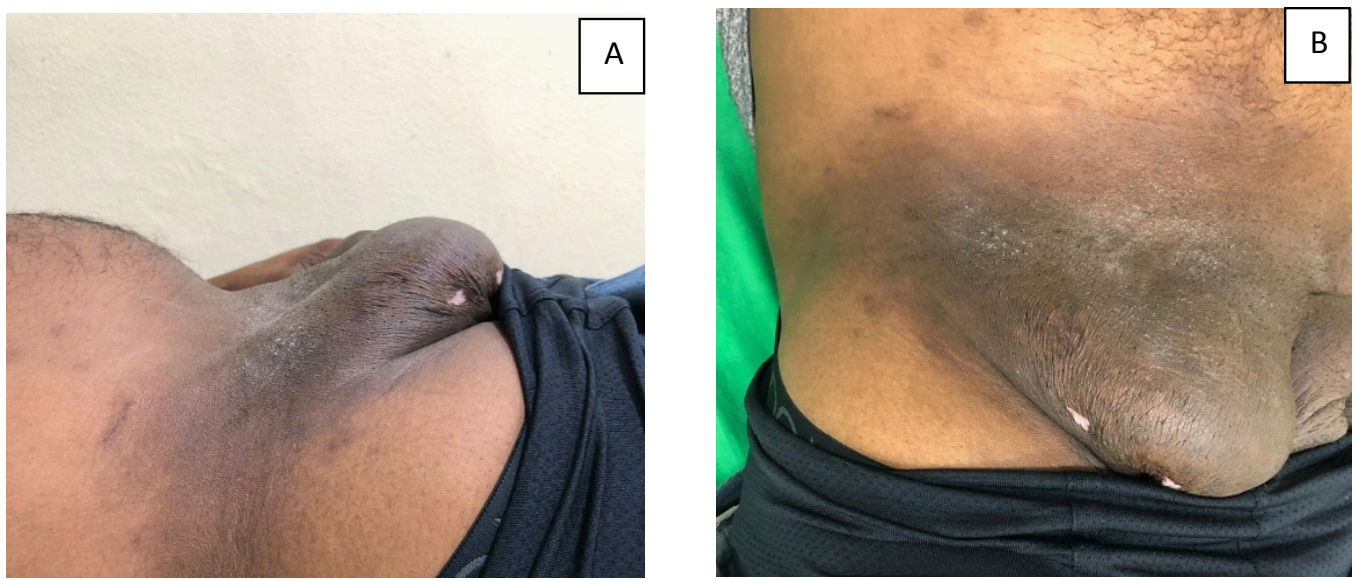

Figura 4A e 4B - Redução da massa bulky após quimioterapia com R-CHOP (Rituximab, Ciclofosfamida, Doxorrubicina, Vincristina e Prednisona). 


\section{Discussão}

O linfoma de Hodgkin (LH) é uma neoplasia maligna rara de células $\mathrm{B}$, que se apresenta, na maioria dos pacientes, como linfadenopatia supradiafragmática. Linfadenopatias retroperitoneal e inguinal ocorrem com menor frequência ${ }^{1}$. Embora o envolvimento linfonodal regional seja o mais comum, sítios extranodais, como baço, fígado, pulmões e medula óssea, podem ser acometidos, seja por invasão ou via hematogênica. Cerca de um terço dos pacientes apresentam sintomas constitucionais, que incluem febre alta, sudorese noturna e perda ponderal ${ }^{2}$.

O LH tem como peculiaridade a característica de apresentar células malignas constituindo a minoria da população celular intratumoral ${ }^{3}$. Para o estabelecimento do diagnóstico, é necessária a identificação de células de Reed-Sternberg (RS), que geralmente são vistas envoltas por rico ambiente celular composto por linfócitos reativos, eosinófilos e histiócitos, no tecido biopsiado. Duas entidades distintas da doença foram definidas, os LH clássicos (LHc) e o incomum LH de Predomínio Nodular Linfocitário (LHPNL) ${ }^{4}$.

Dentro dos LHc, quatro subgrupos foram identificados: LH esclerose nodular, LH celularidade mista, LH depleção linfocitária e LH rico em linfócitos. Estes apresentam como particularidade histopatológica a presença de grandes células de RS multinucleadas em um pano de fundo de células reativas característico ${ }^{5}$.

O Linfoma de Hodgkin de Predomínio Nodular Linfocitário (LHPNL) corresponde a 5\% de todos os Linfomas de Hodgkin (LH), é mais comum no sexo masculino, na meia idade, é caracterizado por um padrão de crescimento nodular ou nodular difuso com grandes células neoplásicas linfo-histiocíticas ou variantes das células de Reed-Sternberg, rodeadas por linfócitos $\mathrm{T}$ CD4+ e positivos para os marcadores CD20, CD22, CD45, CD79a ${ }^{6}$,além da presença de células B reativas no entorno da região nodular ${ }^{7,8}$. Assim, o LHPNL não possui as células típicas de RS, sendo constituído por células linfocíticas e histiocíticas ou células com "núcleo em pipoca" em meio a linfócitos pequenos, diferindose dos LHc, que caracteristicamente apresentam células típicas de Reed-Sternberg e suas variantes em fundo heterogêneo e inflamatório ${ }^{3}$. Outro aspecto a ser ressaltado é que o LHPNL tende a apresentar caráter indolente e melhor prognóstico quando comparado aos $\mathrm{LH}^{9}$.

Do ponto de vista clínico, o LHPNL acomete, principalmente, cadeias linfáticas periféricas, principalmente a região cervical e raramente $\mathrm{o}$ mediastino $^{10,11}$. Além disso, os pacientes frequentemente apresentam recaídas da doença após um longo período de remissão ${ }^{5,7}$ e propensão a uma longa sobrevida global ${ }^{8}$.
No que diz respeito a transformação para o Linfoma Difuso de grandes células B (LDGCB), um tipo de Linfoma Não Hodgkin (LNH), um levantamento mostrou que 3-6\% dos LHPNL irão se transformar em um LDGCB de caráter agressivo ou podem, ainda, apresentar simultaneamente um LHPNL e um LDGCB $^{4}$.

Os LDGCB possuem algumas variantes, como o LinfomaBRico em células T/Histiócitos(LBRCT/H) que possuem semelhanças morfológicas e imunofenotípicas com o LHPNL. Acredita-se que esses tumores possam ter a mesma origem biológica, uma vez que, em alguns casos, é impossível diferenciar com clareza um subtipo do outro. No entanto, é de suma importância que ocorra sua diferenciação, uma vez que o tratamento das duas entidades ocorre de maneira distinta, somado ao fato dos LHPNL se apresentarem, usualmente, em estágios iniciais e possuírem curso indolente, enquanto os LBRCT/H costumam se apresentar em estágios mais avançados e possuem pior prognóstico?.

Inúmeros estudos mostram que o LHPNL irá, eventualmente, se transformar em um LDGCB em 15 a 20 anos após o diagnóstico inicial e o LBRCT/H é o subtipo mais comum a ser transformado ${ }^{10}$. Com relação ao $\mathrm{LBRCT} / \mathrm{H}$, sabe-se que as células $\mathrm{T}$ reativas são CD8+e há apenas algumas células T CD4+, o que auxilia na diferenciação do LHPNL, além do fato das células $\mathrm{T}$ predominarem no entorno, e não as células $\mathrm{B}^{9,11}$.

No paciente do presente estudo, através dos achados histopatológicos e imuno-histoquímicos, houve dificuldade em diferir entre LHPNL e LBRCT/H. Sendo assim, as manifestações clínicas predominaram, uma vez que o paciente em questão apresentou doença avançada e agressiva, sendo mais compatível com LBRCT/H.

\section{Considerações Finais}

É importante o conhecimento científico sobre a possível transformação do linfoma LHPNL em $\mathrm{LBRCT} / \mathrm{H}$, uma vez que cerca de $6 \%$ dos LHPNL irão se transformar em um LDGCB de caráter agressivo ou podem, ainda, apresentar simultaneamente um LHPNL e um LDGCB. Isto pode alterar o curso e a escolha do tratamento, dependendo do tipo histológico da doença, já que o LHPNL e o LDGCB são abordados com protocolos distintos. Deve-se, também, levar em consideração as manifestações clínicas da doença pois, como no estudo em questão, pode haver dúvida diagnóstica através de exames complementares.

No caso, priorizou-se a evolução clínica do paciente na decisão do tratamento, uma vez que os achados histopatológicos e imuno-histoquímicos não foram suficientemente conclusivos na diferenciação entre LHPNL e LBRCT/H. Após escolha do protocolo 
quimioterápico o paciente apresentou satisfatória resposta ao tratamento. Atualmente, encontra-se aguardando PET para melhor definição de resposta e nova proposta terapêutica de consolidação.

O relato apresentado foi aprovado pelo Comitê de Ética E Pesquisa da Universidade de Vassouras, Parecer no. 3.687.036, CAAE 22689319.8.0000.5290, de 6 de novembro de 2019.

\section{Referências}

1. Alonso $\mathrm{C}$ et al. Adult nodular lymphocyte-predominant Hodgkin lymphoma: treatment modality utilization and survival. Cancer medicine. 2018; 7(4):1118-1126.

2. Savage KJ, Mottok A, Fanale M. Nodular lymphocyte predominant Hodgkin lymphoma. Seminars in Hematology. Seminars in Hematology. 2016; 53(3):190-202.

3. Nascimento MMC. Linfoma de Hodgkin predominância linfocitária nodular: aspectos clínicos-epidemiológicos e patológicos. Salvador: Universidade Federal da Bahia, 2012. Trabalho de Conclusão de Curso do curso de Medicina.

4. Das DK et al. A Case of Composite Classical and Nodular Lymphocyte Predominant Hodgkin Lymphoma with Progression to Diffuse Large B-Cell Non-Hodgkin Lymphoma: Diagnostic Difficulty in Fine-Needle Aspiration Cytology. DiagnosticCytopathology. 2017; 45(3):262-266.

5. Ansell SM. Hodgkin Lymphoma: Diagnosis and Treatment. Mayo Clinic Proceedings. 2015; 90(11):1574-1583.

6. Lee AI, LaCasce AS. Nodular Lymphocyte Predominant Hodgkin Lymphoma. The Oncologist.2009; 14(7):739-751.

7. Cotta CV et al. Nodular Lymphocyte Predominant Hodgkin Lymphoma and Diffuse Large B-Cell Lymphoma: A Study of Six Cases Concurrently Involving the Same Site. Histopathology. 2001;59(6): 1194-1203.

8. Huang JZ et al. Diffuse Large B-cell Lymphoma Arising in Nodular Lymphocyte Predominant Hodgkin Lymphoma. A Report of 21 Cases from the Nebraska Lymphoma Study Group. Leukemia\&Lymphoma. 2003;44(11):1903-1910.

9. Hartmann S et al. Nodular Lymphocyte Predominant Hodgkin Lymphoma and T Cell/Histiocyte Rich Large B Cell Lymphoma -Endpoints of a Spectrum of One Disease? PloS one. 2013;8(11): 1-10.

10. Zhao FX. Nodular Lymphocyte-Predominant Hodgkin Lymphoma or T-cell/Histiocyte Rich Large B-cell Lymphoma: The Problem in "Grey Zone" Lymphomas. Int J Clin Exp Pathol. 2008; 1:300-305

11- Rets AV, Gottesman SRS. Nodular Lymphocyte Predominant Hodgkin Lymphoma versus T-Cell/Histiocyte-Rich Large B-Cell Lymphoma: A Diagnostic Challenge. Case Reports in Pathology. 2014. 